\title{
Identification of Differentially Expressed Genes by Proto-oncogene Protein DEK using Annealing Control Primers
}

\author{
Dong-Wook KIM¹, Jaehwi LEE ${ }^{2}$, and Sang-Beom SEO ${ }^{1 *}$ \\ ${ }^{1}$ Department of Life Science, College of Natural Sciences, \\ ${ }^{2}$ Department of Pharmaceuticals, College of Pharmacy, Chung-Ang University, Seoul 156-756, Korea
}

(Received May 30, 2008; Revised July 17, 2008; Accepted July 20, 2008)

\begin{abstract}
The proto-oncogene protein DEK has been implicated in various human disease including cancer. We have shown that DEK induces caspase-dependent apoptosis in Drosophila by regulating histone acetylation. Reverse transcription-polymerase chain reaction (RT-PCR) method based on annealing control primers was used to screen and identify differentially expressed genes (DEGs) in DEK overexpressed HeLa cells. Among the genes identified, clusterin and fibrillarin have major role in apoptosis pathway regulation. TFIIIC and RPS24 are implicated in HAT mediated transcriptional initiation and cololectal cancer, respectively. To further analyze DEK's role in apoptosis, multiplex PCR was performed. Caspase-3, -7 , and -10 and proapoptotic gene bid were newly identified as possible target genes regulated by DEK expression.
\end{abstract}

Keywords: DEK, Apoptosis, Annealing control primer, Differentially expressed gene, GeneFishing

\section{INTRODUCTION}

Initially identified in a fusion with the CAN nucleoporin protein, DEK is involved in acute myelogenous leukemia (AML) subtype with a translocation $(6 ; 9)$ which results in the formation of a DEK-CAN fusion gene (von Lindern et al., 1990). As a nuclear phosphorprotein, DEK possesses the major DNA binding domain (DBD) SAP box, and at least three highly acidic domains (Waldmann et al., 2004). The acidic domain harboring the $\mathrm{N}$-terminal two-thirds of the DEK protein has been shown to be fused to the C-terminal two-thirds of CAN in the DEKCAN fusion protein (von Lindern et al., 1992). We have identified that p300- and PCAF-mediated histone acetylatransferase (HAT) inhibitory activities of DEK through its acidic domain containing regions (Ko et al., 2006). Previous reports have suggested that the DEK proto-oncogene protein performs vital functions in chromatin remodeling, via the alteration of the topology of chromatin (Waldmann et al., 2002). It has been proposed that DEK is one component of a multiprotein transcriptional repressor complex which includes hDaxx and HDAC2 (Hollenbach et al., 2002). Recent report suggests that

\footnotetext{
${ }^{*}$ Corresponding author

Tel: +82-2-820-5242, Fax: +82-2-822-3059

E-mail: sangbs@cau.ac.kr
}

DEK is a target gene of lysine specific demethylase, LSD1 and repressed upon LSD1 knock-down (Scoumanne et al., 2007). Different roles of DEK in various signal transduction pathways have been implicated recently including the modulation of apoptosis through HAT inhibitory activity and DNA damage repair through ADP-ribosylation (Kappes et al., 2008; Lee et al., 2008).

In this study, we have identified and characterized the differentially expressed genes (DEGs) whose expressions were altered by proto-oncogene DEK overexpression using a differential display technique which is based on annealing control primers (ACPs) (Hwang et al., 2003). We have demonstrated that DEK is able to regulate certain number of genes that play major roles in apoptosis pathway.

\section{MATERIALS AND METHODS}

\section{Construction of plasmids}

The coding sequence of DEK was PCR-amplified with ligation of either a 5' BamHI site-introduced primer (5'CGCGGATCCGCGATGTCCGCCTCGGCCCCTGCT-

GCG-3') and a 3' EcoRI site-introduced primer (5'-CGCGAATTCGCGTCAAGAAATTAGCTCTTTTAC-3'). For the eukaryotic expression construct of DEK, PCR product was cloned into the cloning site of PCMX PL1 vector, respectively. Sequences of construct surrounding the 
cloning sites were verified by automated sequencing.

\section{Cell culture and transient transfection}

HeLa cells were grown in Dulbecco's modified Eagle's medium (Gibco) containing 10\% heat-inactivated fetal bovine serum (Gibco) and $0.05 \%$ penicillin-streptomycin (Gibco) at $37^{\circ} \mathrm{C}$ with $5 \% \mathrm{CO}_{2}$ in humidified air. HeLa cells were seeded at $2 \times 10^{5}$ cells/well in 6-well dish and transient transfection to HeLa cells were performed using Lipofectamine 2000 (Invitrogen) with vector control pCMX PL1 $(1 \mu \mathrm{g})$ and PCMX PL1-DEK $(1 \mu \mathrm{g})$ for identification of differentially expressed genes and screening of apoptosis related genes.

\section{RNA isolation}

Total RNA was isolated from untreated, control vector, and DEK transfected HeLa cells for ACP-based PCR analysis and multiplex PCR analysis. Total RNA extraction was carried out using TRIZOL reagent (Invitrogen), according to the manufacturer's instructions.

\section{Annealing control primer (ACP)-based GeneFish- ing ${ }^{\mathrm{TM}}$ PCR}

For identification of differentially expressed genes (DEGs) from DEK overexpressed cells, which were screened by the ACP-based PCR method (Kim et al., 2004) using the GeneFishing ${ }^{T M}$ DEG service (Seegene, Korea). Briefly, total RNA was treated with DNase I at room temperature for $15 \mathrm{~min}$. For the synthesis of first-strand cDNAs, DNase I-treated total RNAs were reverse-transcribed by M-MLV reverse transcriptase. Reverse transcription was performed for $1.5 \mathrm{hr}$ at $42^{\circ} \mathrm{C}$ in a reaction mixture containing $3 \mu \mathrm{g}$ of the total RNA, $4 \mu \mathrm{l}$ of $5 \times$ buffer, $5 \mu \mathrm{l}$ dNTPs (each $2.5 \mathrm{mM}), 2 \mu \mathrm{l}$ of dT-ACP1 $(10 \mu \mathrm{M})$ primer (Table I). Second-strand cDNA synthsis was performed using $1 \mu \mathrm{l}$ of dT-ACP2 $(1 \mu \mathrm{M}), 1 \mu \mathrm{l}$ of 20 arbitrary ACPs (Table I), and 2x Master Mix (Seegene, Korea). After second-strand cDNA synthesis was completed, this was

Table I. Primer sequences used in cDNA synthsis and ACP-based PCR

\begin{tabular}{|c|c|c|}
\hline Primer purpose & Primer name & Sequence (5'-3') \\
\hline Reverse Transcription & dT-ACP1 & CTGTGAATGCTGCGACTACGAT I I I I I(T) $\left.\right|_{18}$ \\
\hline GeneFishing PCR (reverse primer) & dT-ACP2 & CTGTGAATGCTGCGACTACGAT I I I I I(T) $)_{15}$ \\
\hline \multirow[t]{20}{*}{ GeneFishing PCR (forward primer) } & ACP 1 & GTCTACCAGGCATTCGCTTCAT I I I IGCCATCGACC \\
\hline & ACP 2 & GTCTACCAGGCATTCGCTTCAT I I I IAGGCGATGCC \\
\hline & ACP 3 & GTCTACCAGGCATTCGCTTCAT I I I ICCGGAGGATG \\
\hline & ACP 4 & GTCTACCAGGCATTCGCTTCAT I I I IGCTGCTCGCG \\
\hline & ACP 5 & GTCTACCAGGCATTCGCTTCAT I I I IAGTGCGCTCG \\
\hline & ACP 6 & GTCTACCAGGCATTCGCTTCAT I I I IGGCCACATCG \\
\hline & ACP 7 & GTCTACCAGGCATTCGCTTCAT I I I ICTGCGGATCG \\
\hline & ACP 8 & GTCTACCAGGCATTCGCTTCAT I I I IGGTCACGGAG \\
\hline & ACP 9 & GTCTACCAGGCATTCGCTTCAT I I I IGATGCCGCTG \\
\hline & ACP 10 & GTCTACCAGGCATTCGCTTCAT I I I ITGGTCGTGCC \\
\hline & ACP 11 & GTCTACCAGGCATTCGCTTCAT I I I ICTGCAGGACC \\
\hline & ACP 12 & GTCTACCAGGCATTCGCTTCAT I I I IACCGTGGACG \\
\hline & ACP 13 & GTCTACCAGGCATTCGCTTCAT I I I IGCTTCACCGC \\
\hline & ACP 14 & GTCTACCAGGCATTCGCTTCAT I I I IGCAAGTCGGC \\
\hline & ACP 15 & GTCTACCAGGCATTCGCTTCAT I I I ICCACCGTGTG \\
\hline & ACP 16 & GTCTACCAGGCATTCGCTTCAT I I I IGTCGACGGTG \\
\hline & ACP 17 & GTCTACCAGGCATTCGCTTCAT I I I ICAAGCCCACG \\
\hline & ACP 18 & GTCTACCAGGCATTCGCTTCAT I I IICGGAGCATCC \\
\hline & ACP 19 & GTCTACCAGGCATTCGCTTCAT I I I ICTCTGCGAGC \\
\hline & ACP 20 & GTCTACCAGGCATTCGCTTCAT I I I IGACGTTGGCG \\
\hline
\end{tabular}

${ }^{*}$ poly $(\mathrm{I})$, The polydeoxyinosine Linkers and representation of deoxyinosine. 
subjected to second-stage PCR amplification. The amplified PCR products were separated in $2 \%$ agarose gel stained with ethidium bromide.

\section{Cloning and sequencing}

Differentially expressed bands were purified from gels using the GENECLEAN ${ }^{\circledR}$ ॥ Kit (Q-BIO gene) and were cloned into TOPO TA cloning vector (Invitrogen) according to the manufacturer's instructions. Sequencing of these clones was performed using ABI PRISM 3100 Genetic Analyzer (Applied Biosystems). The DNA sequence of each gene was analyzed by searching for similarities using the BLAST at the National Center for Biotechnology Information GenBank.

\section{Apoptosis-related gene muliplex PCR}

Multiplex PCR was performed using the Human apoptosis gene group (Cat. No. MH1900) of GeneXPTM service (Seegene, Korea). Briefly, $0.5 \mu \mathrm{g}$ of total RNA were reverse-transcribed for the first-strand CDNA synthesis with $1 \mu \mathrm{l}$ oligo-dT-ACP (Seegene, Korea) and M-MLV reverse transcriptase. The reaction mixture were containing $1 \mu \mathrm{l}$ of RNase inhibitor, $4 \mu \mathrm{l}$ of $5 \times \mathrm{RT}$ buffer, $2 \mu \mathrm{l}$ of dNTP (each $2.5 \mathrm{mM}$ ), $2 \mu \mathrm{l}$ of $1 \mathrm{M}$ DTT. The synthesized cDNAs were used as templates of muliplex PCR using the following condition: one cycle at $94^{\circ} \mathrm{C}$ for $15 \mathrm{~min}, 40$ cycles of $\left(94^{\circ} \mathrm{C}\right.$ for $30 \mathrm{sec}, 63^{\circ} \mathrm{C}$ for $1 \mathrm{~min} 30 \mathrm{sec}$, and $72^{\circ} \mathrm{C}$ for $1 \mathrm{~min} 30 \mathrm{sec}$ ), and then on final cycle at $72^{\circ} \mathrm{C}$ for 10 min with $5 \times$ Human APOP-X primer mix (Seegene, Korea). Housekeeping genes (ACTB, B2M, GAPD, SDHA, and RPL13A) were used as internal controls.

\section{RESULTS AND DISCUSSTION}

\section{Differentially expressed genes by DEK overexpres- sion}

To identify genes that are differentially expressed in the presence of DEK overexpression, we compared the mRNA expression profiles of untreated, CMX PL1 control, and CMX PL1-DEK transfected HeLa cells. First, overexpression of DEK in HeLa cell compared to the untreated and CMX PL1 empty vector transfected was confirmed by RT-PCR (Fig. 1A). Total RNA from each cells for ACP based PCR were compared (Fig. 1B). ACP technology based on the unique tripartite structure of a specific oligonucleotide primer, which has 3'- and 5'- distinct portions separated by a regulator, specifically targets sequence hybridization to the template via a polydeoxyinosine linker.

Using a combination of 20 arbitrary primers of two
(A)

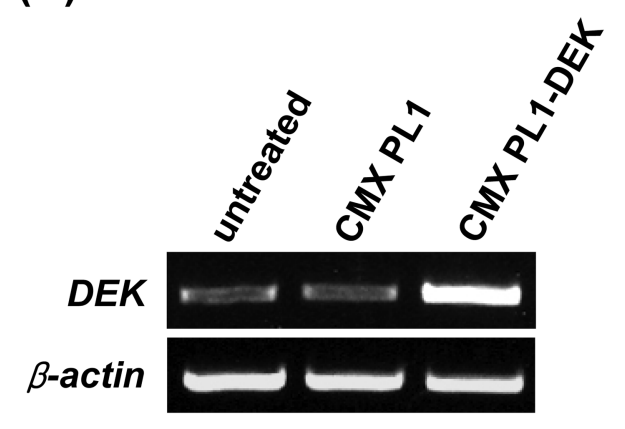

(B)

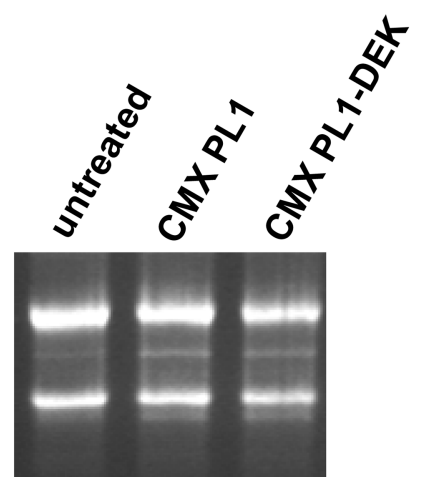

Fig. 1. DEK overexpression in the transfected cells and isolation of RNA (A) Overexpression of DEK in the HeLa cells was confirmed by RT-PCR using DEK specific primers. The $\beta$-actin was used as a control for equal RNA amounts. (B) Electrophoresis of total RNA from each sample (untreated, CMX PL1, and CMX PL1-DEK transfected cells).

anchored oligo (dT) primers of ACP-based GeneFishing PCR kit, we isolated 11 DEGs in DEK overexpressed HeLa cell (Fig. 2). Among the 11 DEGs analyzed, 4 DEGs (DEG2, 4, 7, and 11) which showed significant change in their expression were cloned and sequenced for identification. BLAST search revealed that some of the cloned genes or ESTs had significant sequence similarities with known genes in the GenBank (Table II).

One of the differentially expressed genes in DEK overexpressed cell (DEG 4, Fig. 2 and Table II), clusterin, is ubiquitously expressed in various cells and tissues (de Silva et al., 1990) and it is overexpressed in several human cancers such as prostate (Kadomatsu et al., 1993), breast (Redondo et al., 2000), and ovarian cancer (Hough et al., 2001). Clusterin has been reported to be involved in various biological processes such as carcinogenesis, tumor growth, and apoptotic cell death (Shannan et al., 2006). Recent report shows that knock down 

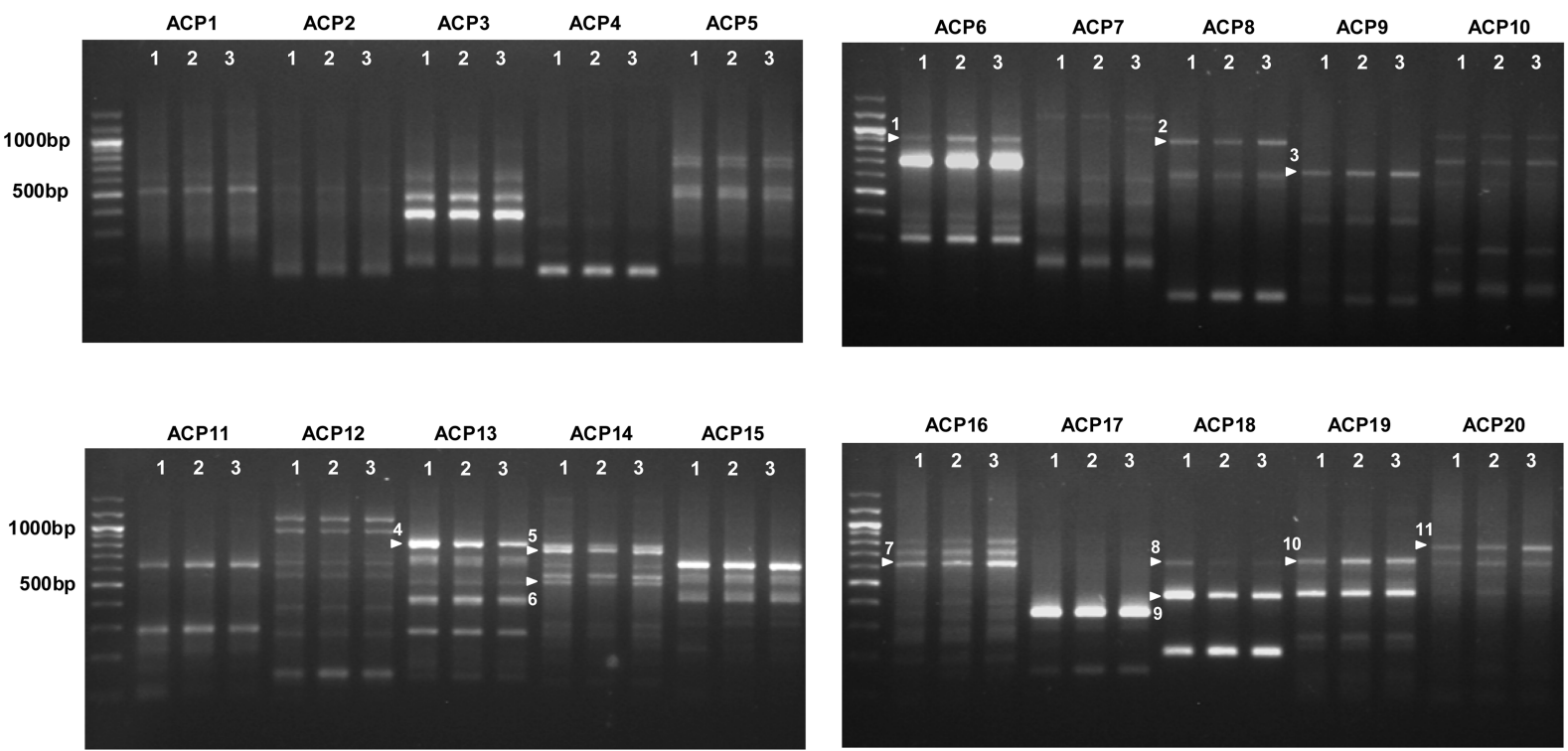

Fig. 2. Annealing control primer (ACP)-based PCR for the identification of differentially expressed genes (DEGs) from DEK overexpressed HeLa cells. Using 20 ACPs (as a arbitrary forward primer) and a dT-ACP2 (as a reverse primer), 11 differentially expressed genes (white arrowheads) were identified in DEK overexpressed cells. Four of them were cloned and sequenced for identification. (1, untreated; 2, CMX PL1; 3, CMX PL1-DEK).

Table II. Identification of differentially expressed genes (DEGs) in DEK transfected HeLa cells

\begin{tabular}{cclc}
\hline DEG No. & Accession No. & \multicolumn{1}{c}{ Gene } & \multicolumn{1}{c}{ Identities } \\
\hline DEG 2 & BC019260.1 & $\begin{array}{l}\text { Homo sapiens fibrillarin, mRNA (cDNA clone MGC:2347 IMAGE:3504198), } \\
\text { complete cds Length=1163 }\end{array}$ & 806/808 (99\%) \\
\hline DEG 4 & NM_001831.2 & $\begin{array}{l}\text { Homo sapiens clusterin (Complement lysis inhibitor, SP-40,40, sulfated } \\
\text { glycoprotein 2, testosterone-repressed prostate message 2, apolipoprotein J) } \\
\text { (CLU), transcript variant 1, mRNA Length=2859 }\end{array}$ & $743 / 743(100 \%)$ \\
\hline DEG 7 & BC094774.1 & $\begin{array}{l}\text { Homo sapiens, polypeptide 4, 90kDa, mRNA (cDNA clone MGC:104675 } \\
\text { IMAGE:4830453), complete cds Length=3082 }\end{array}$ & $508 / 510(99 \%)$ \\
\hline DEG 11 & NM_001026.3 & $\begin{array}{l}\text { Homo sapiens ribosomal protein S24 (RPS24), transcript variant 2, mRNA } \\
\text { Length=593 }\end{array}$ & 468/470 (99\%) \\
\hline
\end{tabular}

of clusterin transcripts via siRNA results in growth retardation and increase of apoptosis, and induces cell sensitization to genotoxic and oxidative stress (Trougakos et al., 2004). On the contrary, it has been suggested that clusterin plays an important role in inhibiting apoptosis in human cancer cells by interfering with pro-apoptotic protein Bax activation, thereby inhibiting cytochrome C release (Zhang et al., 2005). Clusterin was down-regulated in DEK overexpressed cells compared with untreated and CMX PL1 transfected cells. These results suggest that HAT inhibitory activity of proto-oncogene protein DEK negatively effects on promoter and/or transcriptionally regulated region of clusterin as a transcriptional regulator. Our previous report has shown that DEK overexpression in Drosophila in vivo system and HeLa cells induce the apoptotic cell death (Lee et al., 2008). Therefore, down-regulation of clusterin in DEK overexpressed cells may promote the apoptotic cell death through HAT inhibitory activity in their promoter.

The ribosomal protein S24 (RPS24), was up-regulated in DEK overexpressed cells (DEG 11, Fig. 2 and Table II). Ribosomal proteins are a major component of ribosomes, therefore play critical roles in protein biosynthesis. Also, it was involved in various cellular processes such as replication, transcription, RNA processing, and DNA repair. Recently it has been shown that ribosomal proteins were significantly increased in normal mucosa, whereas markedly decreased in colorectal cancer (Kasai et al., 2003). We found that RPS24 expression was significantly increased by DEK overexpression, suggesting 
that it may be involved in DEK-mediated apoptosis through involvement of cellular processes via their extraribosomal functions.

Fibrillarin is a component of the nucleolar small nuclear ribonucleoprotein, which has an important role in prerRNA processing and ribosome assembly during ribosomal biogenesis (Lafontaine et al., 2000). Recent report observed that fibrillarin would play a critical role in the maintenance of nuclear shape and cellular growth in human cells and mouse (Newton et al., 2003; Amin et al., 2007). In our study, fibrillarin expression was slightly increased when DEK was overexpresed (DEG 2, Fig. 2 and Table II). This increase may be due to the DEKmediated apoptosis for cell protection. General transcription factor IIIC (TFIIIC) (DEG 7, Fig. 2 and Table II) expression was highly increased, which has HAT activity with specificity towards histone H3 (Hsieh et al., 1999). Elevation of TFIIIC expression level in DEK transfected cell suggests that the effect might be a response against elevated histone deacetylation level by HAT inhibitory activity of DEK and towards the maintenance of histone acetylation level.
Screening of apoptosis related genes using multiplex PCR

We have previously reported the role of DEK in caspase-mediated apoptosis in Drosophila and human carcinoma cell using genetic and biochemical analyses (Lee et al., 2008). DEK overexpression induces caspasedependent apoptotic cell death in Drosophila as well as HeLa cell through capase- 9 and -3 activation. To further elucidate the role of DEK in apoptosis pathway, we performed screening of expression patterns of apoptosis related genes using GeneXP analysis (Seegene, Korea) (Fig. 3). DEK overexpressed cells showed substantial increase of certain caspase series such as caspase-3, -7, and -10. In addition, pro-apoptotic protein bid was enhanced its expression level in DEK overexpressed cells, which triggers apoptosis by cytochrome $\mathrm{C}$ release and mitochondria damage such as loss of the membrane potential. Taken together, elevation of caspase-3, -7 , and -10 and bid expression reinforce our previous report that DEK induces apoptotic cell death through caspase-dependent pathway.
(A)

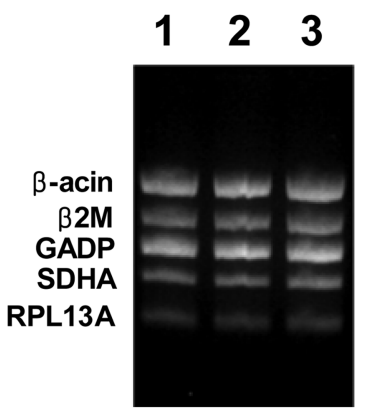

(D)

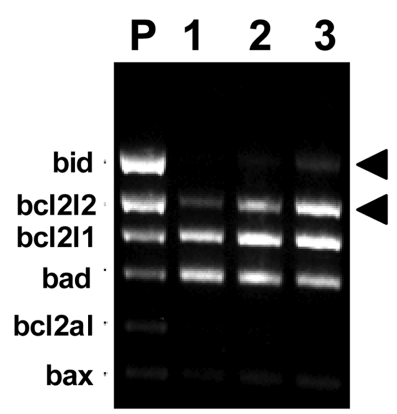

(B)

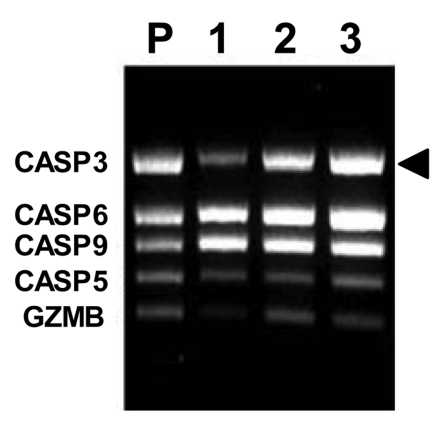

(E)

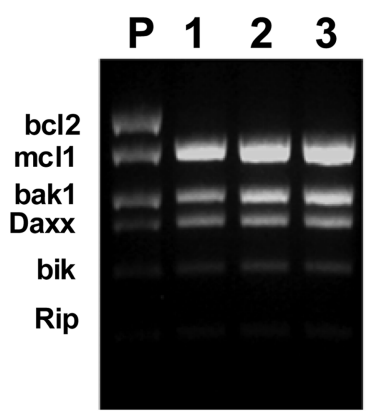

(C)

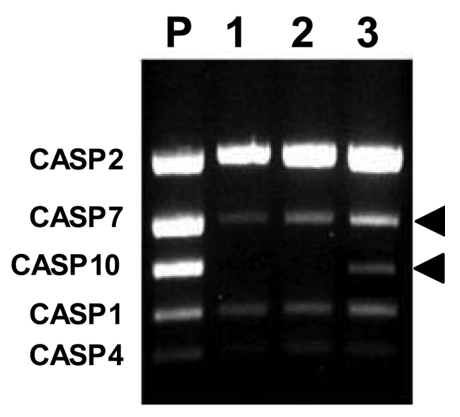

(F)

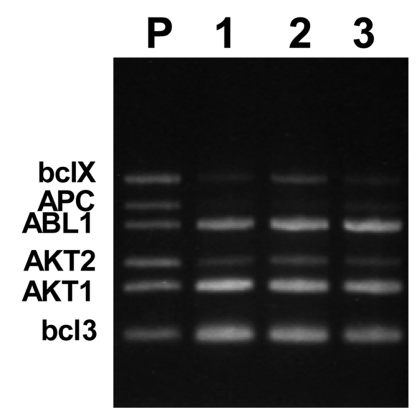

Fig. 3. Screening of apoptosis related genes using multiplex PCR. (A) House keeping genes (B2M, $\beta$-2-microglobulin; GAPD, glyceraldehydes-3-phosphate dehydrogenase; SDHA, succinate dehydrogenase complex, subunit A; RPL13A, ribosomal protein L13a) were used as controls for equal RNA amounts in these analysis. Arrowheads indicate the bands showing significant changes in their expression. (P, positive control; 1, untreated; 2, CMX PL1; 3, CMX PL1-DEK). 


\section{ACKNOWLEDGEMENTS}

This study was supported by a grant from Chung-Ang University (2007).

\section{REFERENCES}

Amin, M.A., Matsunaga, S., Ma, N., Takata, H., Yokoyama, M., Uchiyama, S., and Fukui, K. (2007). Fibrillarin, a nucleolar protein, is required for normal nuclear morphology and cellular growth in HeLa cells. Biochem. Biophys. Res. Commun. 360, 320-326.

de Silva, H.V., Harmony, J.A., Stuart, W.D., Gil, C.M., and Robbins, J. (1990). Apolipoprotein J: structure and tissue distribution. Biochemistry 29, 5380-5389.

Hollenbach, A.D., McPherson, C.J., Mientjes, E.J., lyengar, R., and Grosveld, G. (2002). Daxx and histone deacetylase II associate with chromatin through an interaction with core histones and the chromatin-associated protein Dek. J. Cell. Sci. 115, 3319-3330.

Hough, C.D., Cho, K.R., Zonderman, A.B., Schwartz, D.R., and Morin, P.J. (2001). Coordinately up-regulated genes in ovarian cancer. Cancer Res. 61, 3869-3876.

Hsieh, Y.J., Kundu, T.K., Wang, Z., Kovelman, R., and Roeder, R.G. (1999). The TFIIIC90 subunit of TFIIIC interacts with multiple components of the RNA polymerase III machinery and contains a histone-specific acetyltransferase activity. Mol. Cell. Biol. 19, 7697-7704.

Hwang, I.T., Kim, Y.J., Kim, S.H., Kwak, C.I., Gu, Y.Y., and Chun, J.Y. (2003). Annealing control primer system for improving specificity of PCR amplification. Biotechniques 35 , 1180-1184.

Kadomatsu, K., Anzano, M.A., Slayter, M.V., Winokur, T.S., Smith, J.M., and Sporn, M.B. (1993). Expression of sulfated glycoprotein 2 is associated with carcinogenesis induced by $\mathrm{N}$-nitroso-N-methylurea in rat prostate and seminal vesicle. Cancer Res. 53, 1480-1483.

Kappes, F., Fahrer, J., Khodadoust, M.S., Tabbert, A., Strasser, C., Mor-Vaknin, N., Moreno-Villanueva, M., Burkle, A., Markovitz, D.M., and Ferrando-May, E. (2008). DEK is a poly(ADP-ribose) acceptor in apoptosis and mediates resistance to genotoxic stress. Mol. Cell. Biol. 28, 3245-3257.

Kasai, H., Nadano, D., Hidaka, E., Higuchi, K., Kawakubo, M., Sato, T.A., and Nakayama, J. (2003). Differential expression of ribosomal proteins in human normal and neoplastic colorectum. J. Histochem. Cytochem. 51, 567-574.

Kim, Y.J., Kwak, C.I., Gu, Y.Y., Hwang, I.T., and Chun, J.Y. (2004). Annealing control primer system for identification of differentially expressed genes on agarose gels. Biotechniques 36, 424-426.

Ko, S.I., Lee, I.S., Kim, J.Y., Kim, S.M., Kim, D.W., Lee, K.S., Woo, K.M., Baek, J.H., Choo, J.K., and Seo, S.B. (2006).
Regulation of histone acetyltransferase activity of p300 and PCAF by proto-oncogene protein DEK. FEBS Lett. 580, 3217-3222.

Lafontaine, D.L. and Tollervey, D. (2000). Synthesis and assembly of the box $\mathrm{C}+\mathrm{D}$ small nucleolar RNPs. Mol. Cell. Biol. 20, 2650-2659.

Lee, K.S., Kim, D.W., Kim, J.Y., Choo, J.K., Yu, K., and Seo, S.B. (2008). Caspase-dependent apoptosis induction by targeted expression of DEK in drosophila involves histone acetylation inhibition. J. Cell Biochem. 103, 1283-1293.

Newton, K., Petfalski, E., Tollervey, D., and Caceres, J.F. (2003). Fibrillarin is essential for early development and required for accumulation of an intron-encoded small nucleolar RNA in the mouse. Mol. Cell. Biol. 23, 8519-8527.

Redondo, M., Villar, E., Torres-Munoz, J., Tellez, T., Morell, M., and Petito, C.K. (2000). Overexpression of clusterin in human breast carcinoma. Am. J. Pathol. 157, 393-399.

Scoumanne, A. and Chen, X. (2007). The lysine-specific demethylase 1 is required for cell proliferation in both p53-dependent and -independent manners. J. Biol. Chem. 282, 1547115475.

Shannan, B., Seifert, M., Leskov, K., Willis, J., Boothman, D., Tilgen, W., and Reichrath, J. (2006). Challenge and promise: roles for clusterin in pathogenesis, progression and therapy of cancer. Cell Death Differ. 13, 12-19.

Trougakos, I.P., So, A., Jansen, B., Gleave, M.E., and Gonos, E.S. (2004). Silencing expression of the clusterin/apolipoprotein j gene in human cancer cells using small interfering RNA induces spontaneous apoptosis, reduced growth ability, and cell sensitization to genotoxic and oxidative stress. Cancer Res. 64, 1834-1842.

von Lindern, M., Breems, D., van Baal, S., Adriaansen, H., and Grosveld, G. (1992). Characterization of the translocation breakpoint sequences of two DEK-CAN fusion genes present in $\mathrm{t}(6 ; 9)$ acute myeloid leukemia and a SET-CAN fusion gene found in a case of acute undifferentiated leukemia. Genes Chromosomes Cancer 5, 227-234.

von Lindern, M., Poustka, A., Lerach, H., and Grosveld, G (1990). The $(6 ; 9)$ chromosome translocation, associated with a specific subtype of acute nonlymphocytic leukemia, leads to aberrant transcription of a target gene on 9q34. Mol. Cell. Biol. 10, 4016-4026.

Waldmann, T., Eckerich, C., Baack, M., and Gruss, C. (2002). The ubiquitous chromatin protein DEK alters the structure of DNA by introducing positive supercoils. J. Biol. Chem. 277, 24988-24994.

Waldmann, T., Scholten, I., Kappes, F., Hu, H.G, and Knippers, R. (2004). The DEK protein--an abundant and ubiquitous constituent of mammalian chromatin. Gene 343, 1-9.

Zhang, H., Kim, J.K., Edwards, C.A., Xu, Z., Taichman, R., and Wang, C.Y. (2005). Clusterin inhibits apoptosis by interacting with activated Bax. Nat. Cell Biol. 7, 909-915. 